\title{
Influence of Aging Temperature on Metallurgy, Impact Toughness and Pitting Behavior of Flux-Cored Arc Welded 2205 Duplex Stainless Steel Joint
}

\author{
Yingying Zhang ${ }^{1,2}$, Zhengjun Liu ${ }^{1, *}$ and Dongming $\mathrm{Li}^{2}$ \\ ${ }^{1}$ School of Materials Science and Engineering, Shenyang University of Technology, Shenyang 110870, China \\ ${ }^{2}$ School of Mechanical Engineering, Liaoning Petrochemical University, Fushun 113001, China
}

This study systematically investigated the effect of aging temperature on microstructure, impact toughness and pitting behavior of fluxcored arc welded 2205 duplex stainless steel joint. $600^{\circ} \mathrm{C}-900^{\circ} \mathrm{C}$ aging treatments were carried out with 1 -hour insulation. The results showed that the ferrite $(\alpha)$ underwent serial metallurgical transformations with increasing the aging temperature. The formation of the sigma ( $\sigma$ ) phase was detected in the weld zone (WZ) under all aging temperatures due to eutectoid reaction of the $\alpha$ phase, while the peak content of the $\sigma$ phase was reached at $800^{\circ} \mathrm{C}$ aging. A similar content variation of the $\sigma$ phase was detected in the heat-affected zone (HAZ). Secondary austenite ( $\gamma 2$ ) and chi $(\chi)$ phases were only observed in the WZ and $\mathrm{HAZ}$ below $800^{\circ} \mathrm{C}$ aging. The impact toughness and the pitting resistance of the welded joints were strongly related to the $\sigma$ phase content, that the $800^{\circ} \mathrm{C}$ aging specimen possessed the lowest impact toughness and the worst corrosion resistance due to the maximum content of the $\sigma$ content in both the WZ and the HAZ. [doi:10.2320/matertrans.MT-M2020331]

(Received October 25, 2020; Accepted March 25, 2021; Published May 14, 2021)

Keywords: duplex stainless steel, aging, phase change, impact property, corrosion resistance

\section{Introduction}

Duplex stainless steels (DSSs), which consist of a nearly equal proportion of ferrite $(\alpha)$ and austenite $(\gamma)$ phases, are usually used in chemical, petrochemical, nuclear, food industries, etc. due to their superior performance of higher strength, toughness and high corrosion resistance than conventional austenitic stainless steels. ${ }^{1-3)}$ Compared with the austenitic stainless steels, the hot cracking tendency during welding of DSSs is weaker. ${ }^{4)}$ In comparison to ferritic stainless steel, the DSSs possess lower ductile-brittle transition temperature, better resistance to intercrystalline corrosion and pitting corrosion. In addition, the DSSs retain high thermal conductivity and small linear expansion coefficient, benefitting to excellent weldability. ${ }^{3,5}$ )

For DSSs, the role of various alloying elements such as chromium $(\mathrm{Cr})$, nickel $(\mathrm{Ni})$ and nitrogen $(\mathrm{N})$ plays a critical role in their weldability via adjusting the $\alpha / \gamma$ phase balance, due to high alloying contributed precipitation of intermetallic phases like carbides and nitrides of $\mathrm{Cr}\left(\mathrm{Cr}_{23} \mathrm{C}_{6}\right.$ and $\left.\mathrm{Cr}_{2} \mathrm{~N}\right)$, chi $(\chi)$ and sigma $(\sigma) .{ }^{6-11)}$ It was reported that the $\sigma$ phase occurred in binary $\mathrm{Fe}-\mathrm{Cr}$ system, while the $\chi$ phase could be found only in ternary $\mathrm{Fe}-\mathrm{Cr}-\mathrm{Mo}$ and quaternary $\mathrm{Fe}-\mathrm{Cr}-\mathrm{Ni}-$ $\mathrm{Mo}$ and $\mathrm{Fe}-\mathrm{Cr}-\mathrm{Ni}-\mathrm{Ti}$ systems. ${ }^{7,12)}$ These precipitates affect the properties of DSSs in varying degrees. Thereinto, the $\sigma$ phase is the largest amount of precipitation and leads to the greatest harm to the material properties such as ductility, toughness, and corrosion resistance..$^{9,13,14)}$

Welded joints play a crucial role during the application of DSSs, which can determine the whole structural performance to a certain extent. However, improper high-temperature exposures or heat treatment procedures of the welds can occur during their unanticipated service processes, which will produce undesirable precipitations and result in the decrease of the joint performance. ${ }^{15}$ ) Therefore, the research of the influence of postwelding aging treatment on the metallurgy is considerable to comprehend the evolution of joint properties.
However, most of the current studies paid close attention to the effects of aging on the intermetallic precipitation, while systematic studies on the evolution of comprehensive properties such as impact toughness and corrosion resistance are relatively few in DSSs joints, especially in flux-cored arc welded joint. ${ }^{15,16)}$ Therefore, the present work aims to systematically investigate the influence of aging temperature on the evolution of metallurgy, impact toughness and pitting behavior of flux-cored arc welded 2205 DSS joint.

\section{Experimental Procedure}

2205 duplex stainless steel with a thickness of $12 \mathrm{~mm}$ was used as the base material (BM) and ER2209 flux-cored wire with $1.2 \mathrm{~mm}$ diameter was adopted during flux-cored arc welding (FCAW). The main chemical composition of the base metal and the welding wire is shown in Table 1. It can be seen that the Ni content of the welding wire is significantly higher than that of the base material. Before welding, a single $\mathrm{V}$ groove was machined with an angle of $60^{\circ}$ and both sides of the groove were polished by a stainless steel grinding wheel. As sketched in Fig. 1, the distance between the two plates for welding was $2 \mathrm{~mm}$, and the length of the root face was $1 \mathrm{~mm}$. Acetone was used to clean oxidation film, grease and impurities on the plate surfaces.

A digital inverter welder (YD-350FR) was used to supply welding power and a direct current (DC) reverse connection method was adopted during welding. Detailed welding parameters are shown in Table $2 . \mathrm{CO}_{2}$ with a purity of $99.99 \%$ was employed as the shielding gas to protect the

Table 1 Chemical composition of the 2205 DSS and ER 2209 (mass\%).

\begin{tabular}{lllllllll}
\hline Materials & $\mathrm{C}$ & $\mathrm{Si}$ & $\mathrm{Mn}$ & $\mathrm{Cr}$ & $\mathrm{Ni}$ & $\mathrm{Mo}$ & $\mathrm{N}$ & $\mathrm{Fe}$ \\
\hline 2205 & 0.015 & 0.37 & 1.39 & 22.35 & 5.66 & 3.22 & 0.16 & Bal. \\
ER 2209 & 0.021 & 0.63 & 1.07 & 22.56 & 7.98 & 4.33 & 0.15 & Bal. \\
\hline
\end{tabular}




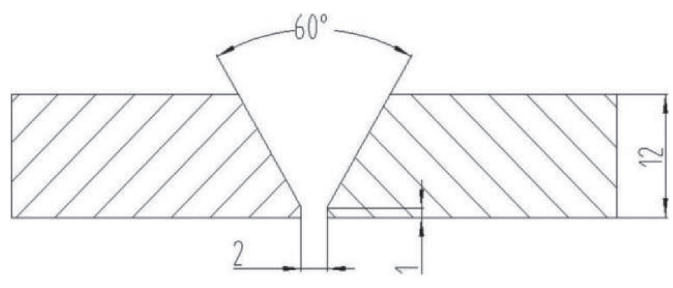

Fig. 1 Schematic of the weld configuration.

Table 2 Detailed welding parameters during the FCAW.

\begin{tabular}{llll}
\hline Filler metal & Welding current & Welding voltage & Welding speed \\
& (A) & (V) & $\left.(\mathrm{cm} \mathrm{min})^{-1}\right)$ \\
\hline ER2209 & 180 & 26 & 23 \\
\hline
\end{tabular}

weld. During the formation of the joint, multi-layer and multi-pass process was taken on and the interpass temperature was not more than $150^{\circ} \mathrm{C}$. After welding, the welded joints were subjected to aging treatment under $600^{\circ} \mathrm{C}, 700^{\circ} \mathrm{C}$, $800^{\circ} \mathrm{C}$ and $900^{\circ} \mathrm{C}$ respectively. After 1-hour heat preservation, the samples were quenched in water for cooling to the room temperature.

The microstructures of the welded joints were observed via a scanning electron microscope (SEM) equipped with energy dispersive spectroscopy (EDS). X-ray diffraction (XRD) was used to acquire the joint phase variation characteristics during the aging treatment. Subsize impact specimen with V-notch and specimen size of $7.5 \mathrm{~mm} \times 10 \mathrm{~mm} \times 55 \mathrm{~mm}$ following ASTM E23-16b standard ${ }^{17)}$ was used for testing the impact properties of the $\mathrm{WZ}$ metal under $-40^{\circ} \mathrm{C}$. Pitting corrosion test was conducted according to ASTM G48-11(2015) standard. ${ }^{18)}$ The joint samples prepared by metallographic polishing were etched with $6 \%$ ferric chloride solution. The spot corrosion rate was calculated by the weight loss per unit area and per unit time of the sample before and after etching in units of $\mathrm{g} /\left(\mathrm{m}^{2} \mathrm{~h}\right)$.

\section{Results and Discussion}

\subsection{Microstructure evolution}

Figure 2 shows the microstructural characteristics of the as-welded joint. The BM consisted of an $\alpha+\gamma$ duplex structure. The $\alpha$ phase was distributed in the $\gamma$ phase matrix with band or island shape (Fig. 2(a)). Similarly, the weld zone (WZ) also showed an $\alpha+\gamma$ duplex structure, while its phase size was slightly coarser than that of the BM (Fig. 2(b)). As shown in Fig. 2(c), the heat-affected zone (HAZ) also showed $\alpha$ and $\gamma$ phases, but its duplex structure was larger than that of the WZ. Besides, a few carbides were observed in the $\alpha$ phase. These two phenomena were due to the high-temperature exposure induced grain growth and precipitation of the second phase during the FCAW.

Figure 3 shows the microstructural characteristics of the welded joint aged at $600^{\circ} \mathrm{C}$. As can be seen in Fig. 3(a), the WZ consisted of a duplex structure of $\alpha+\gamma$ without obvious precipitation of the second phase such as $\sigma$ and $\chi$, which was similar to the as-welded joint. However, two more precipitated phases of $\sigma$ and $\chi$ phases were found in the HAZ except for the $\alpha+\gamma$ matrix phases (Fig. 3(b)). In the magnified views of the precipitated phases, the $\sigma$ phase and $\chi$ phase were observed at the boundary of ferrite and austenite, and a few formed in the interior of the $\alpha$ phase (Fig. 3(c), (d)). It is generally considered that the $\sigma$ phase was formed during the eutectoid reaction of $\alpha \rightarrow \sigma+\gamma 2$, where $\gamma 2$ indicates secondary austenite. ${ }^{14,19)}$
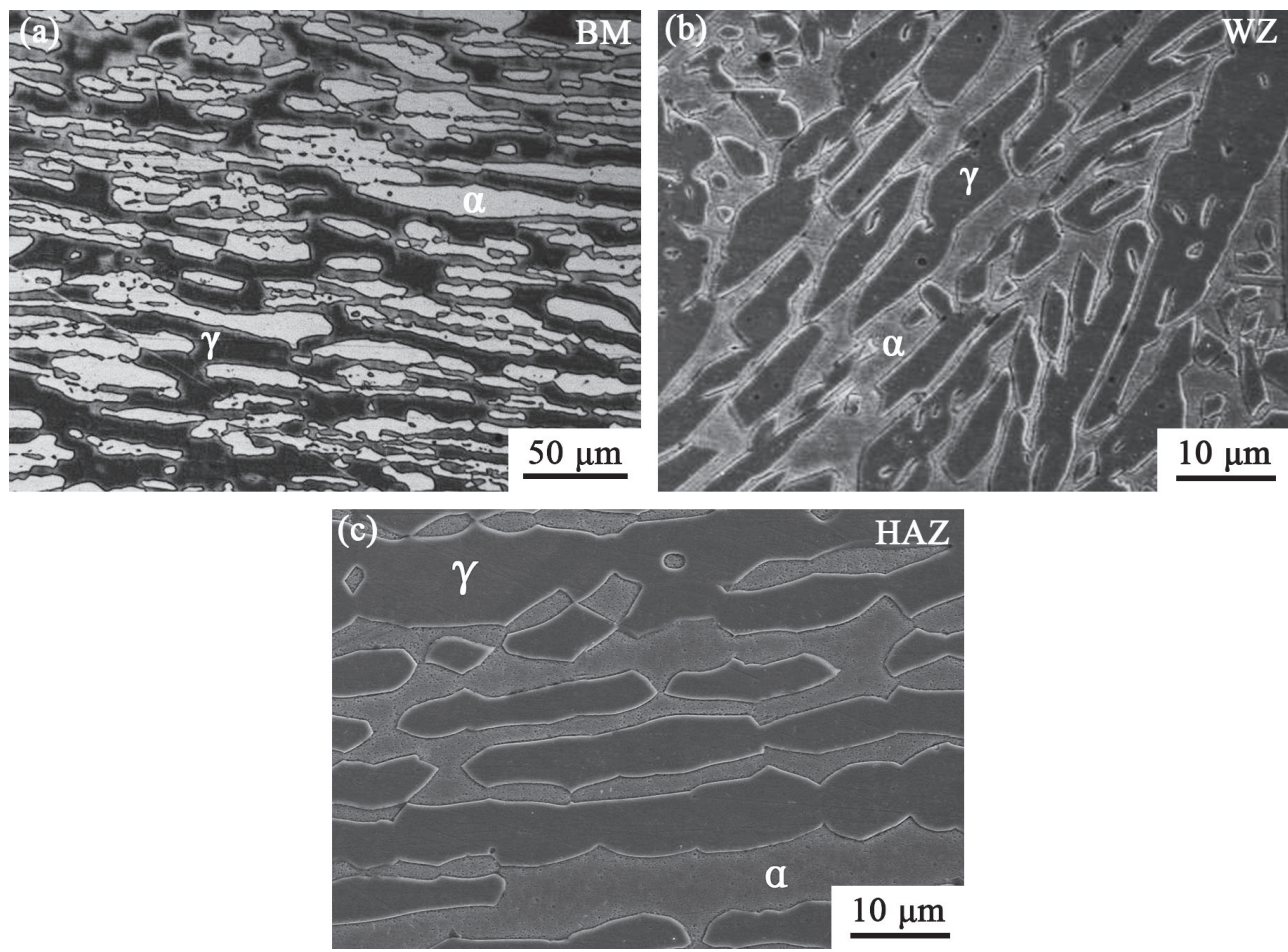

Fig. 2 SEM microstructures of the as-welded joint. 

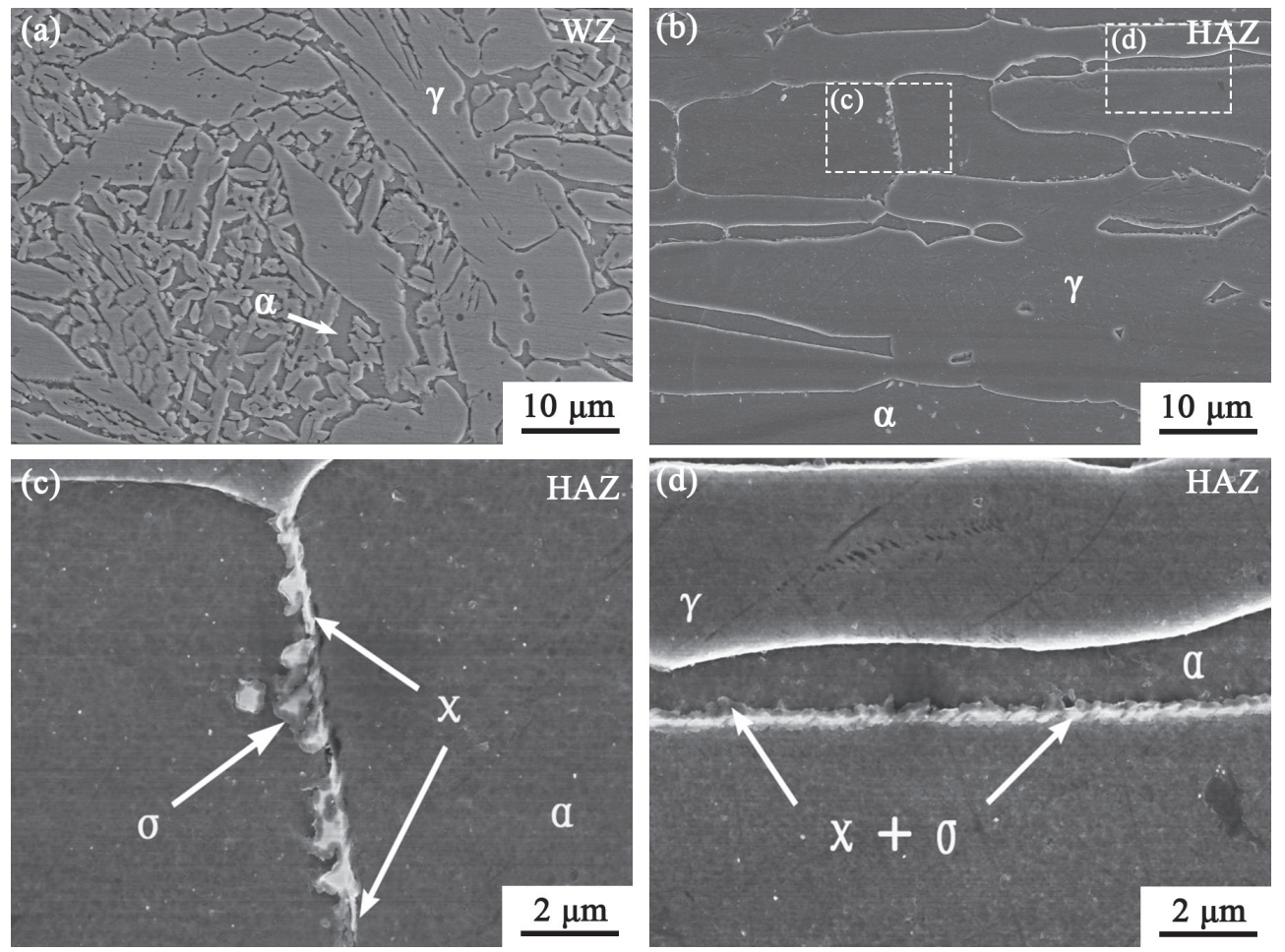

Fig. 3 SEM microstructures of the welded joint aged at $600^{\circ} \mathrm{C}$.

In terms of the morphologies of the precipitated phases in the SEM image, the strip-like $\chi$ phase was whiter than the sheet-like $\sigma$ phase but showed a smaller size surrounded by the $\sigma$ phase. $^{7)}$ The $\chi$ phase is a kind of metastable phase, which can further transform into the $\sigma$ phase with increasing the aging time. That is to say that the $\chi$ phase forms before the precipitation of the $\sigma$ phase and disappears once the $\sigma$ phase starts to precipitate, as also declared by Escriba et al. ${ }^{7)}$ and Okafor et l. $^{12)}$ In addition, Llorca-Isern et al. ${ }^{20)}$ pointed out that there was a great difference in alloy content for the $\sigma$ phase and the $\chi$ phase. The $\sigma$ phase possesses higher content of $\mathrm{Cr}$ element than $\chi$ phase even than the matrix phases of the $\alpha$ and $\gamma$, while the $\chi$ phase owns a higher Mo element than the other phases.

Figure 4(a) shows microstructures of the $\mathrm{WZ}$ after $700^{\circ} \mathrm{C}$ aging treatment. It can be seen that the $\sigma$ phase ratio was significantly higher than the WZ and HAZ microstructures after the $600^{\circ} \mathrm{C}$ aging treatment. Except for the $\sigma$ phase, the $\gamma 2$ phase was also found in the $\alpha$ phase, which was another product of the eutectoid reaction.

In the HAZ, $\sigma$ and $\gamma 2$ phases were also found, while most of the $\sigma$ phases were located at the phase boundaries of the $\alpha$ and $\gamma$, and the $\gamma 2$ phase was few and located in the $\alpha$ phase with rod shape (Fig. 4(b), (c)). Due to the diffusion coefficient of alloy element across the phase boundary was higher than that at the grain boundary, the $\mathrm{Cr}$ and Mo were first enriched near the phase boundary where the $\sigma$ phase preferred to nucleate and grow up. ${ }^{21)}$

Besides, carbides were also formed inside the $\alpha$ phase with dark particles (Fig. 4(c)), which were generally considered as $\mathrm{M}_{23} \mathrm{C}_{6}$ type. ${ }^{19}$ ) The precipitation of the carbides would cause $\mathrm{Cr}$ deficiency areas near the grain boundaries, which could promote the migration of the original phase boundaries and contribute to the formation of the intermetallic phase. No significant $\chi$ phase was observed in the HAZ, which was due to the rapid diffusion rate of alloy elements of $\mathrm{Cr}$ and Mo with the increase of temperature, while the $\chi$ phase was basically transformed into the $\sigma$ phase as a metastable phase.

After aging treatment of $800^{\circ} \mathrm{C}$, the microstructures of the WZ showed an increasing amount of $\sigma$ phase compared with that of the $700^{\circ} \mathrm{C}$ treatment, and the banded $\sigma$ phases were more widely distributed in the $\gamma$ matrix with smaller size and smoother phase boundaries (Fig. 5(a)). After aging treatment at $800^{\circ} \mathrm{C}$, the $\alpha$ phase disappeared in the $\mathrm{WZ}$, and the phase composition was almost composed of $\sigma+\gamma$. For verifying the formation of the $\sigma$ phase, element distribution was measured via EDS shown that the concerned phase possessed high content of $\mathrm{Cr}$ and Mo (Fig. 6), which was the mean feature of the $\sigma$ phase. $^{20)}$ As shown in Fig. 5(b), large block $\sigma$ phases formed in the HAZ and were coarser than that of the $700^{\circ} \mathrm{C} \mathrm{HAZ}$. In addition, no carbide particle was found inside the $\alpha$ phase in the $\mathrm{HAZ}$, indicating that the carbide was hard to precipitate at $800^{\circ} \mathrm{C}$.

After $900^{\circ} \mathrm{C}$ aging treatment, the $\sigma$ phase in the $\mathrm{WZ}$ gathered around the $\gamma$ phase while its proportion was significantly decreased (Fig. 7(a)). The size of the $\gamma$ phase increased during the high-temperature duration. Similar to the $800^{\circ} \mathrm{C}$ treated joint, the block $\sigma$ phase was found in the $\mathrm{HAZ}$, and no carbide particle and was observed in the $\alpha$ phase. However, the content of the block $\sigma$ phase was lower than that of the $800^{\circ} \mathrm{C} \mathrm{HAZ} \mathrm{(Fig.} \mathrm{7(b)).}$

Figure 8 shows the XRD results of the $\mathrm{WZs}$ after $600^{\circ} \mathrm{C}$, $700^{\circ} \mathrm{C}, 800^{\circ} \mathrm{C}$, and $900^{\circ} \mathrm{C}$ aging treatment, respectively. For $700^{\circ} \mathrm{C}, 800^{\circ} \mathrm{C}$ and $900^{\circ} \mathrm{C}$ parameters, the intensity of the $\alpha$ phase was very low and the phases were almost composed of $\gamma$ and $\sigma$, indicating that the significant transformation of the $\alpha$ phase during the eutectoid reaction. Figure 9 shows the 

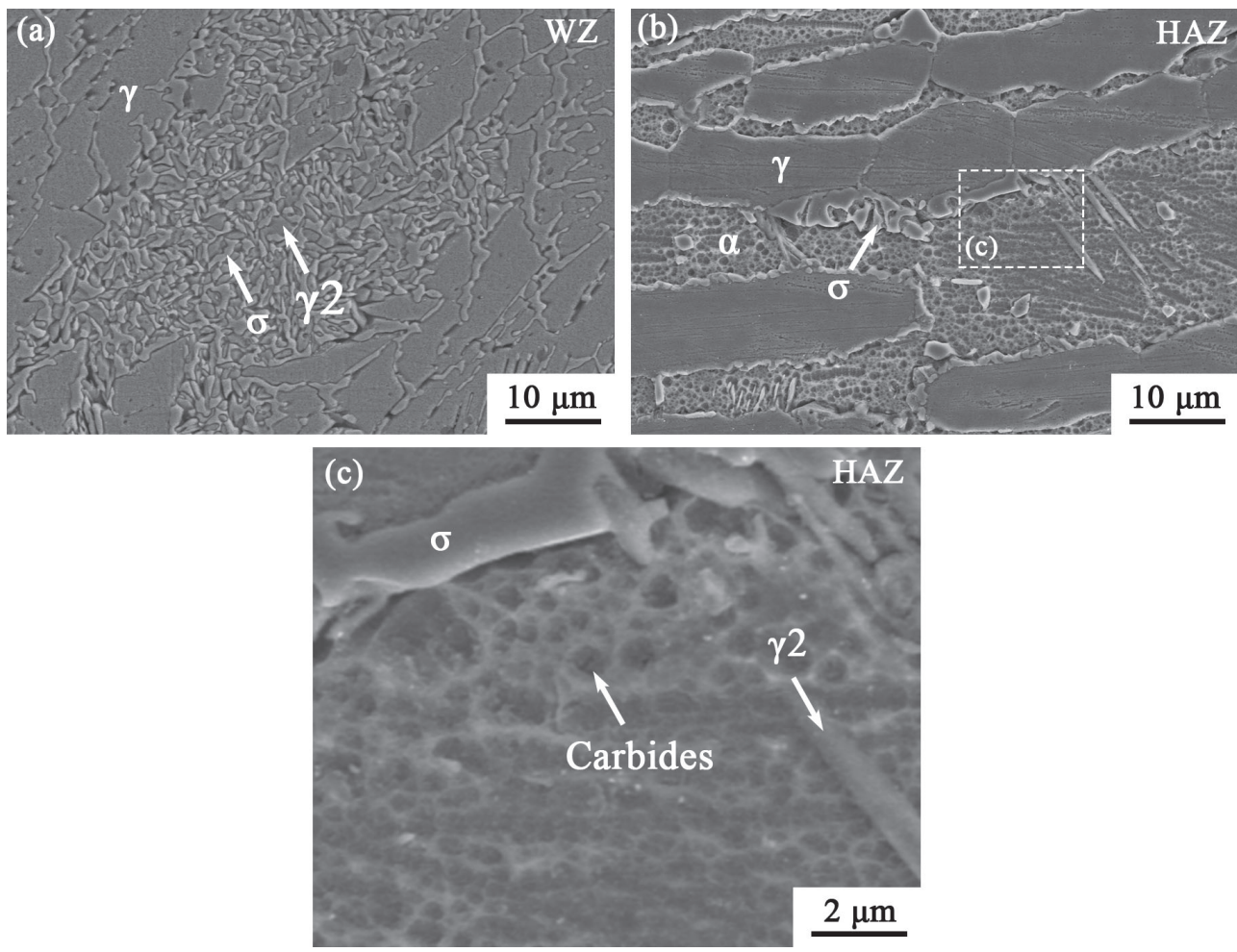

Fig. 4 SEM images of the welded joints aged at $700^{\circ} \mathrm{C}$.
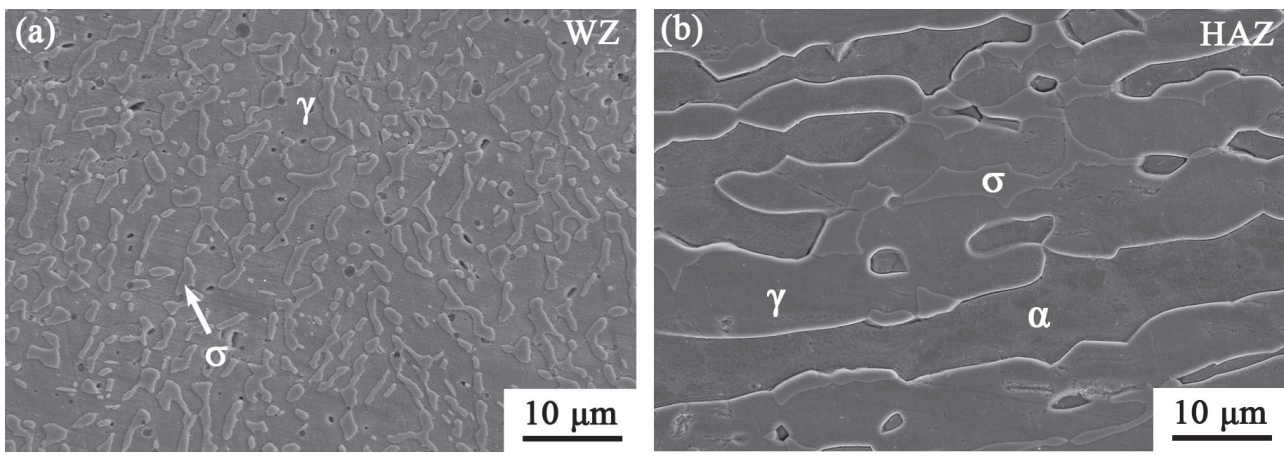

Fig. 5 SEM images of the welded joints aged at $800^{\circ} \mathrm{C}$.

XRD results of the HAZs. It was clear that almost no $\sigma$ phase was observed in the $\mathrm{HAZ}$ after $600^{\circ} \mathrm{C}$ treatment, which was not consistent with the SEM results of Fig. 3. This was due to the extremely low content of the $\sigma$ phase in the sample. Under the $700^{\circ} \mathrm{C}$ and $900^{\circ} \mathrm{C}$ parameters, the diffraction peaks of the $\sigma$ phase became pronounced, and the medium aging temperature of $800^{\circ} \mathrm{C}$ promoted the highest peak intensity of the $\sigma$ phase, which was consistent with the SEM results.

Because the content was very low, the quantitative analysis of the $\sigma$ phase was hard to perform in this study. Thus, we calculated the $\sigma$ phase variation for the WZ metal by using Thermo-Calc software. As shown in Fig. 10, the $\sigma$ phase content of the WZ increased with increasing aging temperature and reached the maximum of $25.8 \%$ over $700^{\circ} \mathrm{C}$ $\left(735^{\circ} \mathrm{C}\right)$. It was clear that the aging temperature of the peak $\sigma$ phase content was not consistent with the experimental one $\left(800^{\circ} \mathrm{C}\right)$, which could be related to the calculation deviation and was acceptable in common consideration. In addition, during the eutectoid reaction of $\alpha \rightarrow \sigma+\gamma 2$, $\mathrm{Cr}$ element diffused quickly in $\alpha$ phase and gathered at grain boundaries and $\alpha / \gamma$ phase boundaries, resulting in the formation of the $\sigma$ phase. With the temperature increasing, dynamic equilibrium of $\mathrm{Cr}$ element was reached between $\alpha$ phase interior and $\alpha / \gamma$ phase boundaries, which inhibited the eutectoid reaction and precipitation of $\sigma$ phase. Hence, the $\sigma$ phase was significantly decreased at $900^{\circ} \mathrm{C}$ aging temperature.

\subsection{Weld impact property}

The impact testing results of the aged WZ metals indicated a valley-distribution of the impact work as the temperature increase. The lowest impact work of $9 \mathrm{~J}$ was obtained for the $800^{\circ} \mathrm{C}$ sample, while $33 \mathrm{~J}, 24 \mathrm{~J}$ and $21 \mathrm{~J}$ were measured for the $600^{\circ} \mathrm{C}, 700^{\circ} \mathrm{C}$ and $900^{\circ} \mathrm{C}$ samples, respectively. The valley-distributed impact work was due to the dramatically increased $\sigma$ phase content and the limitative precipitation of the $\sigma$ phase under $600^{\circ} \mathrm{C}, 700^{\circ} \mathrm{C}$, and $900^{\circ} \mathrm{C}$. It is well known that the $\sigma$ phase was a kind of hard and brittle carbide which can strongly decrease materials impact toughness, which 

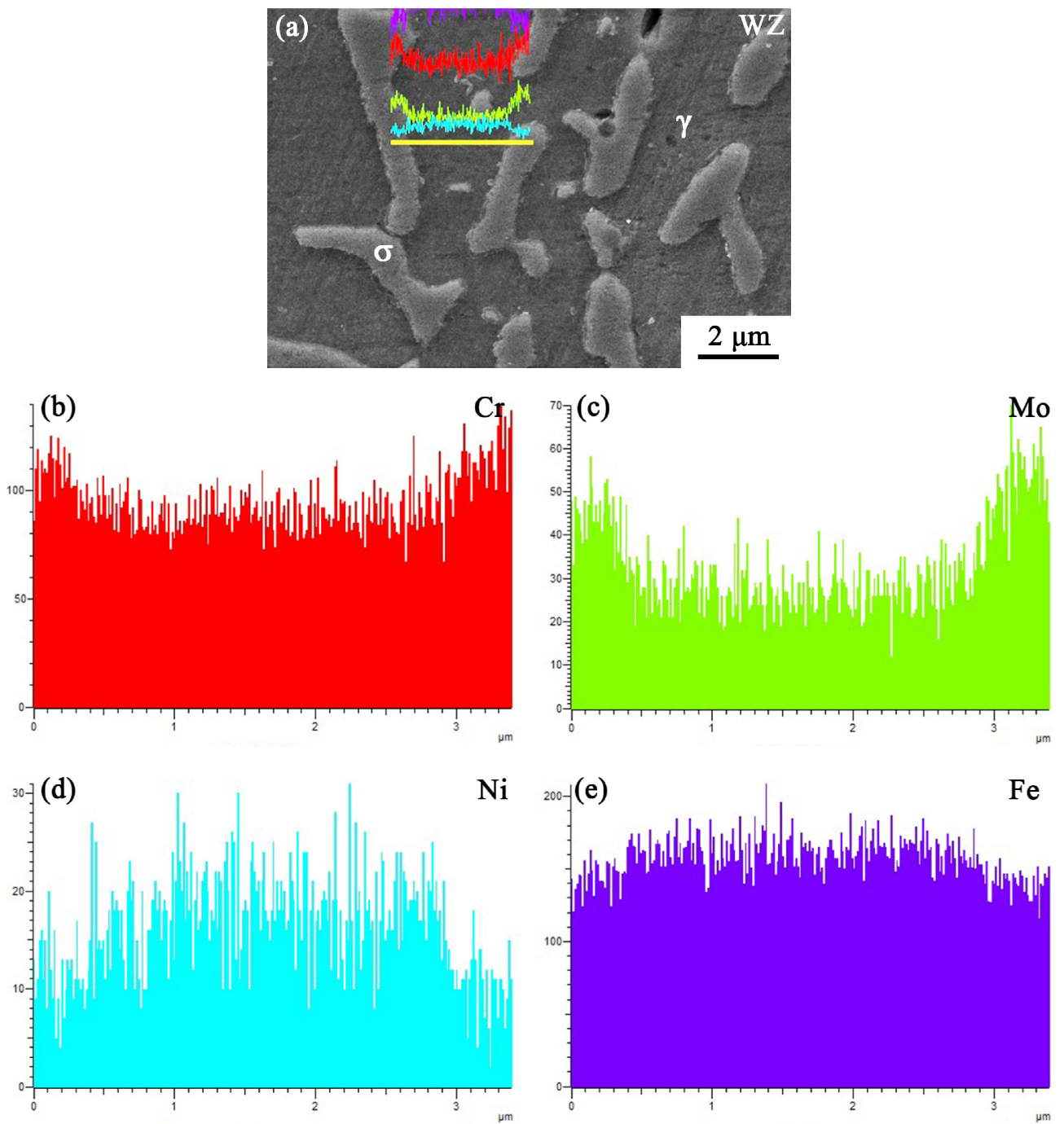

Fig. 6 SEM image combined with EDS line scan results showing the distribution of $\mathrm{Cr}$, $\mathrm{Mo}, \mathrm{Ni}$ and $\mathrm{Fe}$ in the WZ aged at $800^{\circ} \mathrm{C}$.
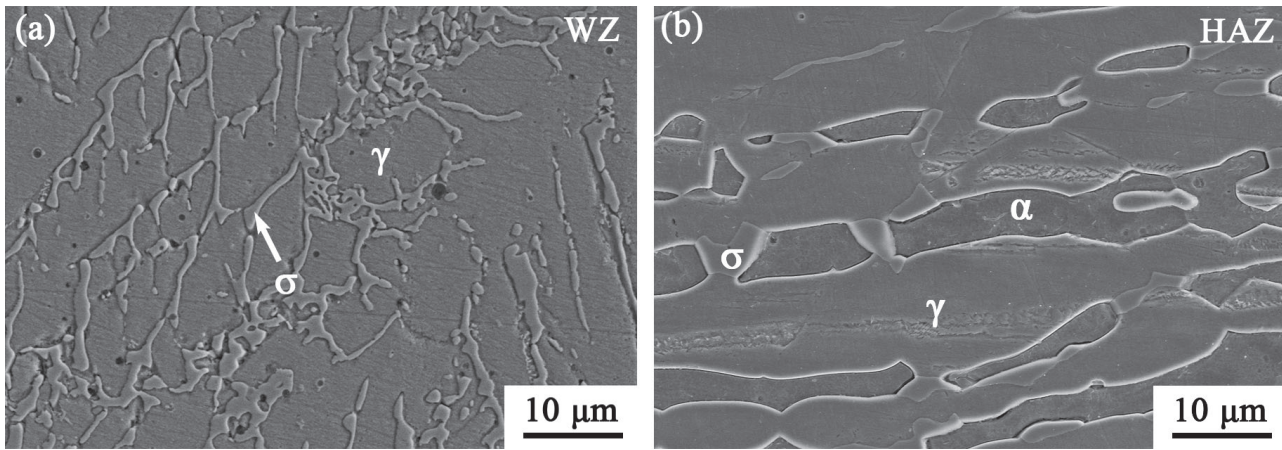

Fig. 7 SEM microstructures of welded joints aged at $900^{\circ} \mathrm{C}$.

leads to premature crack initiation during impact deformation and causes the slip plane gliding fracture phenomena of quasi cleavage. $^{13,22)}$

Figure 11 shows the impact fracture morphologies of the WZ metals at different aging temperatures. According to Fig. 11(a), after $600^{\circ} \mathrm{C}$ aging, the fracture showed a large number of dimples with small and shallow morphology, and few cleavage surfaces were found here. This was corresponding with superior toughness and high import work. However, the dimple was significantly shallow for WZ metals aging after $700^{\circ} \mathrm{C}$ and $900^{\circ} \mathrm{C}$, displaying lower impact toughness than the $600^{\circ} \mathrm{C}$ sample (Fig. $11(\mathrm{~b}),(\mathrm{d})$ ). Therefore, the $700^{\circ} \mathrm{C}$ and $900^{\circ} \mathrm{C} \mathrm{HAZs}$ belonged to the mixed fracture mechanism of ductile fracture and brittle fracture. After $800^{\circ} \mathrm{C}$ aging, the dimple of the HAZ was relatively larger than that of other HAZs. Some dimples were elongated with an opening in a certain direction, which was an embodiment of tearing dimples (Fig. 11(c)). This was a characteristic of transgranular fracture, so the WZ metal showed brittle fracture with low import work. 


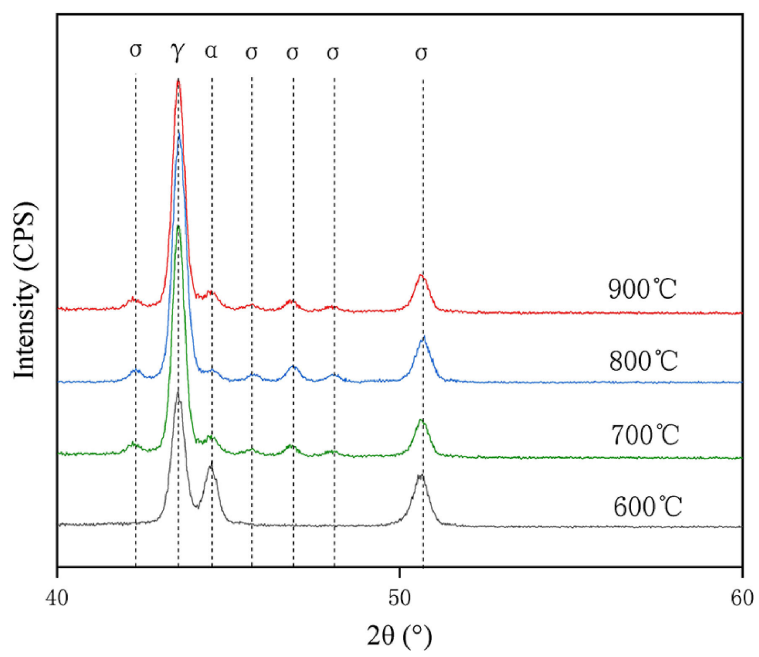

Fig. 8 XRD patterns of the WZs obtained at different aging temperatures.

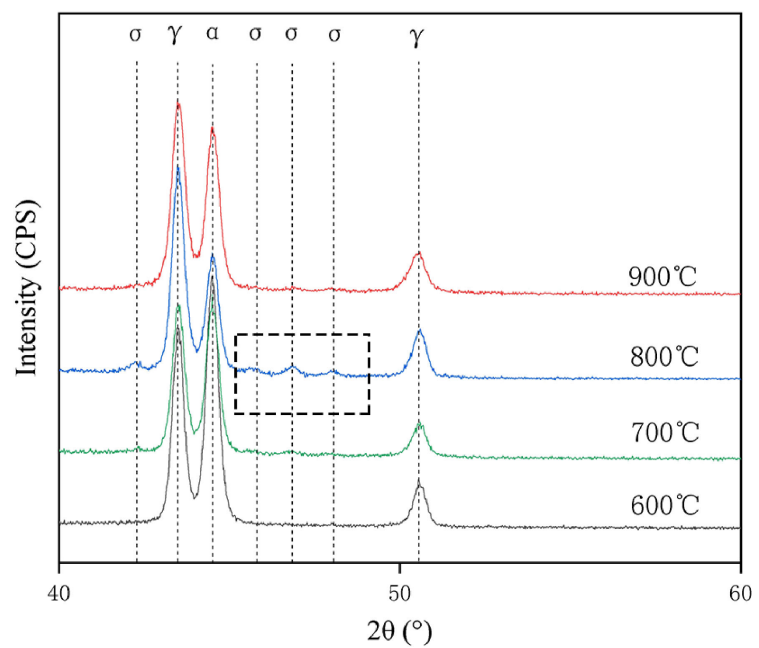

Fig. 9 XRD patterns of the HAZs obtained at different aging temperatures.

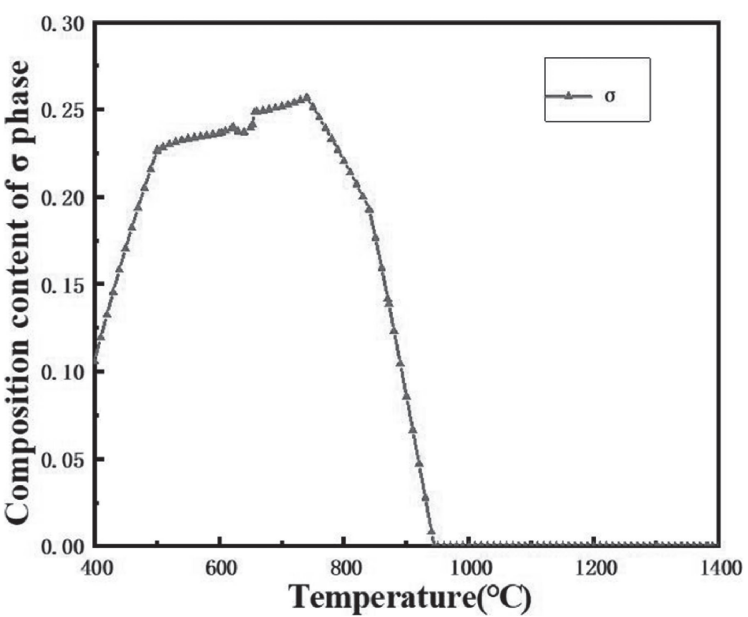

Fig. $10 \sigma$ phase variation in the WZ metal by using Thermo-Calc software.

\subsection{Pitting corrosion resistance}

The corrosion rate of the welded joint samples at different aging temperatures was shown in Table 3. After $600^{\circ} \mathrm{C}$ aging, the corrosion rate of the HAZ and the BM was lower than $2 \mathrm{~g} /\left(\mathrm{m}^{2} \mathrm{~h}\right)$ while the corrosion rate of the WZ was higher. This indicated that the pitting resistance of the HAZ and the $\mathrm{BM}$ was better than that of the WZ, which was also found in other aging specimens. After $700^{\circ} \mathrm{C}$ aging, the corrosion rate of the WZ and the HAZ suddenly increased due to the increased $\sigma$ phase content. Large numbers of the $\sigma$ phases which were full of alloy elements would dilute the surrounding alloying elements such as Cr. Therefore, the pitting resistance in these areas was reduced eventually. After $800^{\circ} \mathrm{C}$ aging, the corrosion rate of the $\mathrm{WZ}$ and the HAZ reached the maximum value, up to $86.063 \mathrm{~g} /\left(\mathrm{m}^{2} \mathrm{~h}\right)$ and $31.842 \mathrm{~g} /\left(\mathrm{m}^{2} \mathrm{~h}\right)$ respectively, indicating the maximum content of the $\sigma$ content in these areas accompanied by the worst corrosion resistance. Figure 12 shows the SEM images of the WZ metal after pitting at different aging temperatures. It was obvious that the $800^{\circ} \mathrm{C}$ aging specimen owned the worst
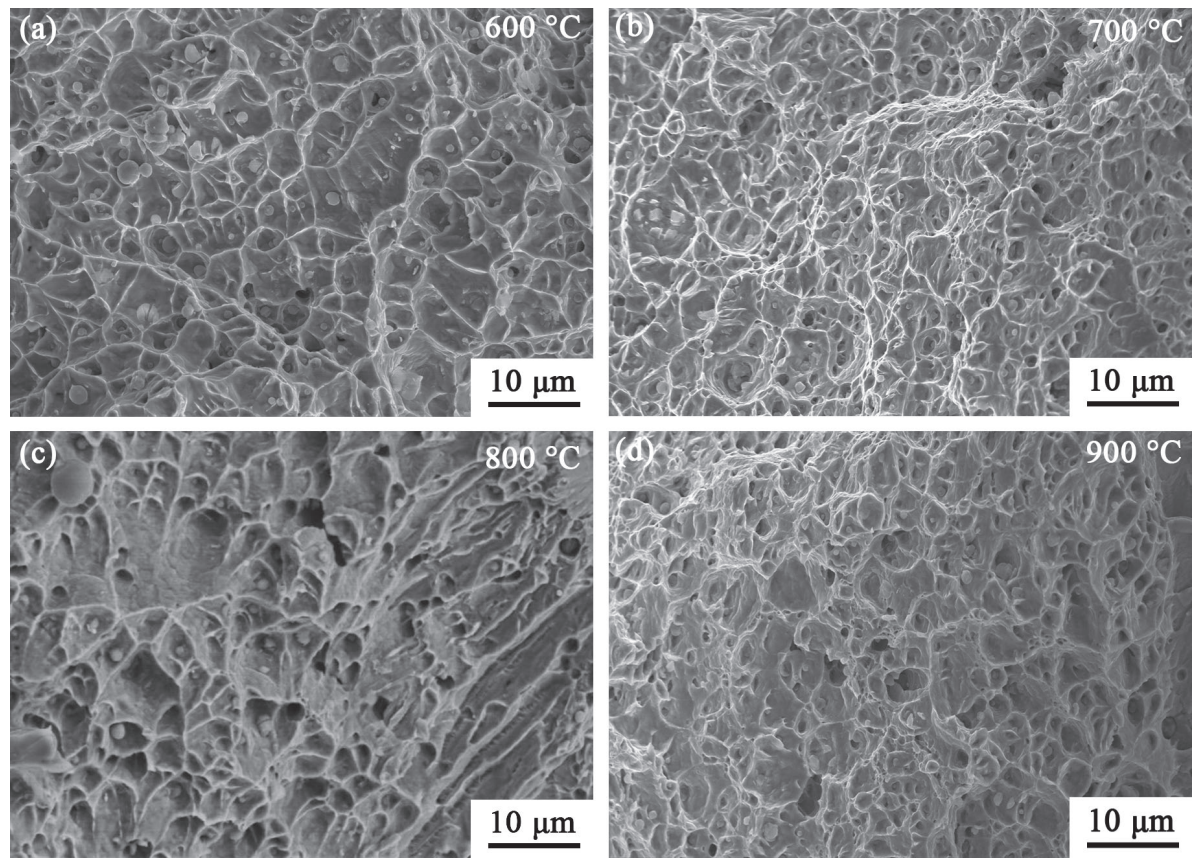

Fig. 11 SEM images of the fractural welds treated at different aging temperatures. 
Table 3 Average corrosion rate of welded joints under different aging treatment $\left(\mathrm{g} /\left(\mathrm{m}^{2} \mathrm{~h}\right)\right)$.

\begin{tabular}{lcccc}
\hline Aging temperatures & $600{ }^{\circ} \mathrm{C}$ & $700{ }^{\circ} \mathrm{C}$ & $800{ }^{\circ} \mathrm{C}$ & $900{ }^{\circ} \mathrm{C}$ \\
\hline WZ & 4.625 & 68.921 & 86.063 & 76.417 \\
$\mathrm{HAZ}$ & 1.684 & 20.679 & 31.842 & 20.975 \\
$\mathrm{BM}$ & 1.492 & 16.854 & 29.7 & 20.171 \\
\hline
\end{tabular}

corrosion resistance with high density of corrosion pits, which was consistent with the corrosion rate testing results mentioned above.

\section{Conclusions}

In the present work, a comprehensive study for the metallurgy, impact toughness and pitting behavior of fluxcored arc welded 2205 duplex stainless steel joint was adopted, and several conclusions could be made:

(1) The aging temperature determined the microstructures of the phase composition of the welds. With the temperature increasing from $600^{\circ} \mathrm{C}$, the $\sigma$ phase content of the welded $\mathrm{WZ}$ and $\mathrm{HAZ}$ increased gradually and reached the maximum at $800^{\circ} \mathrm{C}$ due to the eutectoid reaction of the $\alpha$ phase. After $900^{\circ} \mathrm{C}$ aging, The $\sigma$ content decreased.

(2) The aging temperatures could make a significant effect on the impact toughness of 2205 duplex stainless steel welded joints, which was strongly related to the $\sigma$ phase content. The $800^{\circ} \mathrm{C}$ aging specimen possessed the lowest impact toughness because of the maximum proportion of the $\sigma$ phase.

(3) The aging temperatures also make a significant effect on the pitting resistance of the joints. The $800^{\circ} \mathrm{C}$ aging specimen owned the maximum weight loss and worst corrosion resistance, which was corresponding with the maximum content of the $\sigma$ content in the corresponding areas.
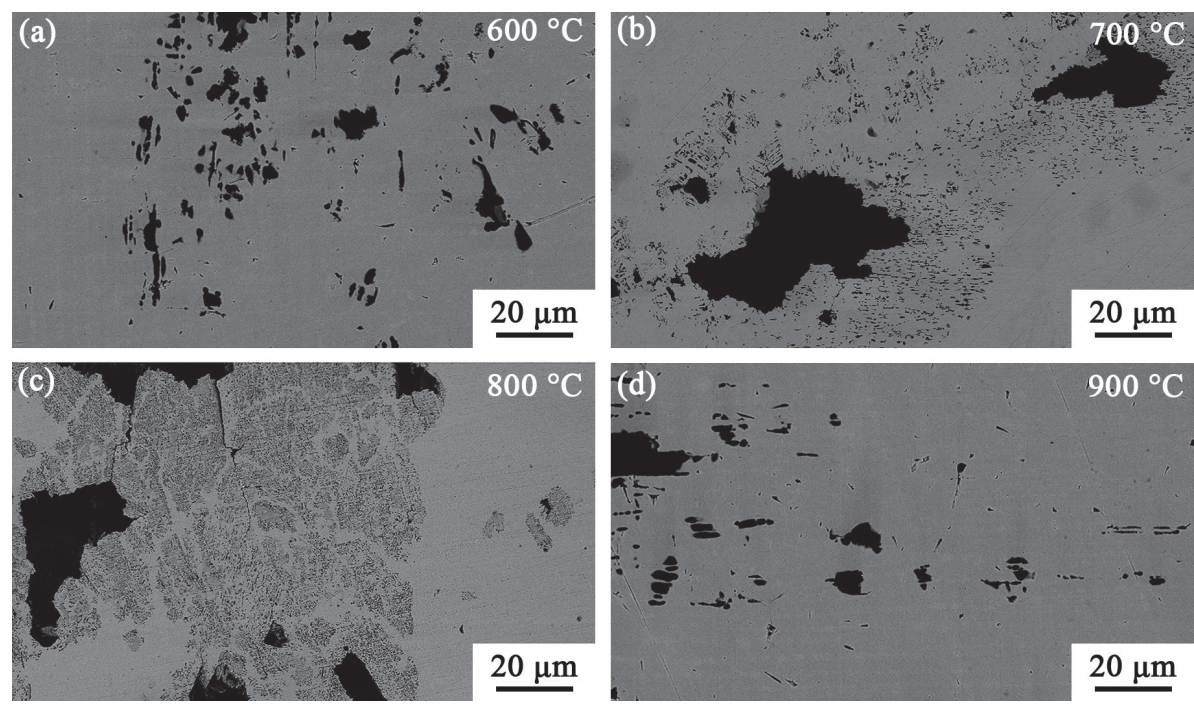

Fig. 12 SEM appearance images of the WZ metal after pitting at different aging temperatures. 